\title{
Antisense inhibitor of apo B has potent lipoprotein effects
}

"Apolipoprotein B (apo B) is the most logical target in lipoprotein metabolism ... [and] everyone has tried to develop small molecules that directly inhibit it," comments John Kastelein, from the Academic Medical Center Amsterdam, the Netherlands. In a small, double-blind, randomized, placebo-controlled, doseescalation trial, Dr Kastelein and colleagues have demonstrated that mipomersen, an antisense inhibitor of apo B synthesis, has potent effects on lipoprotein levels when administered without concomitant statin therapy.

Untreated patients with mild-tomoderate (119-266 mg/dl) hyperlipidemia were randomly assigned to receive placebo $(n=10)$ or mipomersen at doses of $50 \mathrm{mg} /$ week $(n=8), 100 \mathrm{mg} /$ week $(n=8)$, $200 \mathrm{mg} /$ week $(n=8), 300 \mathrm{mg} /$ week $(n=8)$, or $400 \mathrm{mg} /$ week $(n=8)$ over a 13 -week period. Compared with placebo, significant reductions of $15 \%$, $45 \%, 61 \%$ and $71 \%$ in LDL-cholesterol levels and $22 \%, 46 \%, 61 \%$, and $71 \%$ in apo B levels were observed in the 100-400 mg/week groups, respectively. Other lipid parameters were also significantly improved.

Of note, although all of the patients assigned the highest dose of mipomersen achieved LDL-cholesterol levels $<100 \mathrm{mg} / \mathrm{dl}$ within the first 10 weeks of treatment, alanine aminotransferase levels $\geq 3$ times the upper limit of normal had been detected on two consecutive occasions in five of the eight patients by this time point; the $400 \mathrm{mg} /$ week regimen was, therefore, discontinued. One patient in the $200 \mathrm{mg} /$ week group and another in the $300 \mathrm{mg} /$ week group also experienced similar elevations in alanine aminotransferase levels. The investigators point out that "further studies are needed to determine whether lowering of apo B by this novel mechanism may in fact predispose to liver transaminase elevations."

The utility of mipomersen has also been assessed in patients with familial hyperlipidemia (FH). "A multinational consortium led by Frederick Raal performed a phase 3 randomized controlled trial in patients with homozygous $\mathrm{FH}$ who were already receiving maximal lipidlowering therapy; we and others have taken it to the much more prevalent heterozygote patient population," explains Kastelein. "LDL-cholesterol levels were reduced by $35 \%$ in the heterozygotes and $25 \%$ in the homozygotes. Although the efficacy seems somewhat less than that seen with monotherapy, that was expected since it was third-line or forth-line therapy in these patient populations."

Applications for the registration of mipomersen for use as an additional therapy in statin-treated patients with $\mathrm{FH}$ have now been submitted to both the FDA and EMA.

Bryony M. Mearns

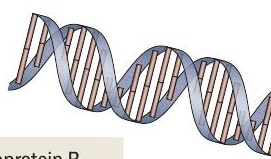

Original article Akdim, F. et al. Efficacy of apolipoprotein B synthesis inhibition in subjects with mild-to-moderate hyperlipidaemia. Eur. Heart J. doi:10.1093/eurheartj/ehr148 